\title{
Delmira Agustini, Ala y Llama
}

$\mathbf{L}^{\wedge}$

A voz musicalmente cálida, densa, que comenzara con vespertinas

notas de alondra - claro augurio de un fin de jornada-, se hizo fúego en el mediodia, gravedad en la tarde, para hundirse - grito desgarrado por urgentes crepúsculos violetas- en la noche apoteósica de Eternidad de la Tragedia.

Melpómene, hierática y maternal, tendía la negrura de su clámide agorera, para cobijar, en espesos pliegues de silencio, la genial testa atormentada. Fué en 1914. E1 6 de julio que recordamos hoy.

El libro blanco, Cantos de la mañana, Los cálices vacíos, El rosario de Eros, Los astros del abismo: éstos fueron sus poemarios. Una alborada de rubores, anuncio de cristal velando significativamente las voces presurosas del instinto. Densidad progresiva del presentimiento de la vida con su sentido patético acuciando el sueño adolescente, colmado de fastuosidades librescas primero, buceando en el yo reflexivo después, para extraer de lo abisal anímico lo incognoscible y vidente empero, de un destino de excepción. Las celulillas cerebrales en una constante emulación de aprendizaje, perseguían, discriminaban la raíz del sueño, ahondando y estructurando formas de arte, ya poderosa la subterránea voz de la sexualidad.

Inconsciente acaso, subía la voz desde el ancestro fiera o paloma que albergamos dentro y que pocos podemos liberar de prejuicios, atavismos, pudores locales, dogmas de sociedad y de religión. La garra quería ser ala, tanto, que se hería en su raíz de carne al tornar, vencido el ímpett. Las fauces sedientas de la criatura liberada, suspiro. Pero, garra y ala y sed y suspiro, fundíanse en la inenarrable angustia de alcanzar la estrella en el pozo, y allá en atmósfera metafísica, trepado el pensamiento en la vertical del sueño, el grito de la 
tierra, fuera y dentro del ser, atraía a la criatura deshumanizada, para. burlarla en el límite de tierra...

$Y$ otra vez la sed. Una sed tremenda de ser exilado en tierra inhóspita y siempre tendida a la cisterna clara. Sueño del viaje prodigioso en la milagrosa barca "sombra" o "estrella" clavada su más alta jarcia en el corazón ardiente de la rosa de los vientos, cerrada y deshecha, sueño de un ensueño repetido . . . blanco, virginal, insexuado, perdidamente deslumbrada de alma, la pobre carne torturada...

Delmira fué la pasión, el estremecimiento, el alarido, el estertor, el sollozo salvaje en la lírica americana. Unica. Con ella y después de ella, altas voces femeninas sin duda ha habido y hay, pero, ni la taciturna soledad hierática de María Eugenia; ni la dolida y honda melopea de Luisa Luisi ; ni la canción juvenil y sonora de Juana primigenia; ni la orfebrería bruñida de Sara de Ibáñez, tuvieron el incontenido sentido de lo universal trágico y cósmico del anhelo humano de la mística ardiente de Delmira. Más que americana, su aparición fué el asombro del mundo poético moderno en que le tocó vivir.

Montevideo, allá en el año 1907, cuando apareció el primer libro de Delmira, era una suerte de gran aldea, que se desperezaba - pupilas asombradas de visiones nuevas - de su vivo dormitar hispano, entre lo vernáculo pintoresco de la tradición criolla y el legado ceñido de algunas fómulas de literatura internacional. El cosmopolitismo de su urbe se insinuaba, acentuando el interés tenso de los países del Plata, por trasvasar esencias finas y residuos transoceánicos ... Los ojos del espíritu se evadían al gran salón de las rutilancias intelectuales europeas. Nos llegaban, por la acústica educada de una minoría, ecos grávidos de músicas nuevas, creando o adulterando formas de un arte sugestivo: la siringa panida de Darío, los jardines versallescos de Herrera y Reissig, el miraje parisino e ingenuo de Minelli, la lisura de mármol ático de Rodó... la audacia verbal e insinuante de Roberto de las Carreras, el pífano de bronce de Lugones, el penacho incaico de Santos Chocano, el madrigal dulce de Papini y Zas ... la prestancia mosqueteril de Falco, el lirismo exuberante de Fernández Ríos, la burbuja sonora de Vasseur . . la taciturna melopea de Asunción Silva, el misticismo cortesano y pulcro de Nervo ... la sensiblera flor de cera de Flores ... la línea griega de Zum Felde, y la hondura analítica de Vaz Ferreira...

$Y$ tantas otras voces de dentro y fuera del continente insinuando otras escuelas y otros ritmos. El art nouveau estilizaba de lánguida 
ortodoxia la rosa mística de la poesía. Un tanto desdeñosas por la pedagogía "geográfica" de nuestros límites, burlones de la lira gazmoña y caduca, entre hisopos de sacristía y excomuniones a la Nueva Musa, libre, arrogante, atrevida, himno a la Belleza desnuda, soberana del pensamiento y de la acción.

Los pebeteros donde se quemaban las milagrosas drogas del parnasianismo y el simbolismo, nos llegaban de lejos a embriagar razón y sentidos. Ya agonizaba la dulzura romántica y se imponía la conciencia de la sensación fuerte, aguda por hermética, compulsando rarezas y extravíos deliciosos de la imagen. Hacía ya decenios que el artista había dejado de sollozar bajo la melancólica languidez del sauce. El poeta nuevo, podía mirar el sol hasta cegarse, afrontar la tormenta, sentirse dueño de su tremendo destino. Y la atmósfera moderna europea, iba sobresaturando de arrestos trascendentes los predios líricos de América.

La pequeña burguesía montevideana dentro del ritmo más lento del continente, hubo de persignarse al principio, asombrada y miedosa, ante los fuegos ígneos de la entusiasta cohorte que, en un alarde de desafío, lanzaba sus explosivos mentales, descubriendo cómo con el barro iluminado de un Baudelaire, la magnificencia hiperestésica de un Poe, el sensualismo pagano de un Samain y el divino ajenjo de un Verlaine, podían reconstruirse, hasta con un verbo dannunziano, fortalezas, castillos, abrir abismos y fosos y cultivar jardines de Klingsor en la América nueva. $Y$ todo muy simplemente: desde la Peña bohemia del viejo Tupinambá o de la tertulia generosa de la editorial Bertani, aquel Mecenas de la bohemia trashumante de las Avenidas. Instrumento de los sueños juveniles de gloria, era el fumino decadente que iba dibujando, audaz, una ruta - como todas las modas que nos llegaban de Europa- un poco más tardia, y con todas las innovaciones imaginadas.

Y fué esa misma turbulenta y simpática pléyade dè poetas la que alzó a Delmira recién aparecida, como una ánfora viva de capitoso embrujo, un plinto de rosas bermejas. La alzó así, arrancándola a la estultez ambiente de la anodina musa casera, para ubicarla para la devota admiración de la posteridad, recogiendo su voz, su libro, su amistad, su presencia, la percepción de su milagroso talento de mujer y poeta.

Impetuosa y consciente de la libertad de su vuelo, no fué una cultora cuidadosa de la forma. Porque el pensamiento, como un duen- 
de indisciplinado, se evadía de fórmulas, tabiques, convencionalismos. Mientras Pérez y Curis alentaba a los ingenuos poetas en agraz con su "Arquitectura del verso", ella decía con una arrogante postura mental, de intuición orgullosa:

La rima es el tirano empurpurado. es el estigma del esclavo; el grillo que acongoja la marcha de la Idea. No aleguéis que es de oro!

El pensamiento

no se esclaviza a un vil cascabeleo: $\mathrm{Ha}$ de ser libre de escalar las cumbres. entero como un dios, la crin revuelta, la frente al sol, al viento. ¿Acaso importa que adorne el ala que le oprime el vuelo?...

Se definía así, en su propio código vital, espontáneo y exuberante. Versos irregulares los más, con todo el sustratum de la lírica contemporánea de la suya, nos queda, empero, el timbal sonoro de su conceptualidad. Olvidamos la forma, el lenguaje a veces desigual entre lo refinado y lo vulgar, porque en Delmira es tan enorme la hondura, que sobrepasa a todos los virtuosismos del lenguaje escrito. $Y$ no nos referimos aquí, para celebrarla, a aquellos muchos de sus versos un tanto barrocos, con influencia de aquel rezago romántico decadente o preciosista sin depuración de esencia, ni tampoco a los de la abigarrada decoración exótica importada de las leyendas miliunésimas... Faz literario-artística de la época, nos quedan como perlas sombrías de mares inconmensurables, los otros, aquellos graves, fuertes, ya madura la fusión entre la vida misma y su sentido estético religioso. Panteísmo extrahumano es el índice de su vocación auténtica.

Potro o cóndor, alta cumbre o llanura vasta, abismo insondable su trasmundo, a veces su verso se electriza de fuego o de escarcha, de llanto o de sombra. Su introversión es la que crea el paisaje jamás sereno ni lánguido. El formalismo, pues, está circunscrito al ímpetu audaz, a la sed, al vuelo mismo, a la fatiga de su aventura cerebral y lírica.

Escuchad su magnífico verso libre "Vida" y el apasionado grito de su sed de sentir:

A ti vengo en mis horas de sed como una fuente limpida, fresca, mansa, colosal. 
$Y$ las punzantes sierpes de fuego mueren siempre en la corriente blanda y poderosa.

Vengo a ti en mi cansancio, como al umbroso bosque en cuyos terciopelos profundos la Fatiga

se aduerme dulcemente con músicas de brisas,

de pájaros y aguas...

$\mathrm{Y}$ del umbroso bosque salgo siempre radiante

y despierta como un amanecer.

Vengo a ti en mis heridas, como el vaso de bálsamos en que el dolor embriaga hasta morir de olvido...

Y llevo,

selladas mis heridas como las bocas muertas

y por tus buenas manos vendadas de delicias...

Cuando el frio me ciñe doloroso sudario,

livida vengo a ti,

como al rincón dorado del hogat,

como al hogar universal del Sol!

$Y$ vuelvo toda en rosas como una primavera,

arropada en tu fuego.

A ti vengo en $\mathrm{mi}$ orgullo

como a la torre dúctil,

como a la torre única,

que me izará sobre las cosas todas:

Sobre la cumbre misma arriscada y creciente

de mi eterno capticho!

Para mi vida hambrienta

eres la presa única,

eres la presa eterna!

El olor de tu sangre,

el color de tu sangre,

flamean en los picos ávidos de mis águilas!

Vengo a ti en mi deseo

como en mil devorantes abismos, toda abierta

el alma incontenible!

$Y$ me lo ofreces todo!

Los mares misteriosos florecidos en astros,

los astros y los mundos!

... Y las constelaciones de espíritus, suspensas

entre mundos $\mathrm{y}$ astros...

$Y$ los sueños que viven más allá de los astros,

MAS ACA de los mundos... 


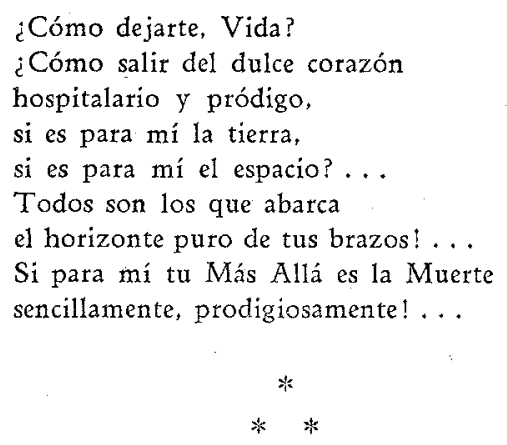

"Para mí tu Más Allá es la Muerte, sencillamente, prodigiosamente", dice ya iniciada en este verso, que es, empero, de una fuerte confianza en las posibilidades de vida ardiente, plena. Zozobra y calma a la que llama su temperamento audaz y exuberante, sombrio y esplendoroso. Amaba la vida tumultuosamente, acaso por esto toda su alma apasionada se tendía por arriba de la Vida misma, arco tenso del deseo de trizar los superpuestos horizontes de los días. Se embriagaba con toda ofrenda vital, gajo ardiente y amargo de Belleza, lengua de diamante para el cristal de los mares y para el acíbar en la ternura, la rebeldía o el dolor. Su trance lírico la transportaba al punto de desangrarse por ella, en torrentes de fuego, en heridas de liz. Puñales ingrávidos la traspasaban. La reacción era la tristeza, como en todo ser hiperestésico, la fuga hacia el silencio, la soledad de las cosas, o la apagada hora del goce sencillo, simple, hogareño, ya aquietado por fatiga su cerebralismo.

Hay a menudo, en su verso, la orgullosa conciencia de su soledad, de su cima, a ella subida en el roce de la tierra:

"Los cuervos negros sufren hambre de carne rosa", dice, y escéptica y desdeñosa, luego de ver "cómo ellos rompen sus picos hambrientos martillando el espejo engañoso... de la luna que refleja su escultura", constata cómo se alejan las sombrías aves "hartas de carne rosa". . . Pero ella ha salvado la esencia intacta de su ser, los cuervos 'se han llevado el fantasma del azogue, jamás su indómita substancia intangible...

Hay, empero, un empeño un tanto pueril en pretender desligar: el desborde subconsciente de la líbido, de las concepciones poéticas de Delmira, llegando en esto, a los panegiristas puritanos que hablan de su fehaciente castidad corporal apenas develada por el Có- 
digo... ¿Qué importancia podría tener eso, si no es para los psicoanalistas, los señores graves que hacen ciencia, pero no versos? No se trata aquí de una historia clínica, sino del grado de reverencia hacia la hondura temperamental de su lírica. ¿Qué importancia añadiría al escuchar sus versos, compulsar cuidadosamente la sensación humana y elemental, humanísima, superhumana, si se trata de un poeta y más aún: si es un poeta genial como lo fué Delmira?

Seguimos creyendo nosotros que la dinámica pasional del genio es el imperativo de volcar, fuera del registro de la conciencia, toda la fuerza cósmica y telúrica de la arcilla atormentada. ¿Qué haría aquí, pues, el casillero de lo cuotidiano vulgar frente a un ser excepcional que vive su complejo superior por arriba de lo establecido por la moral corriente y gazmoña, más allá del bien o del mal, tan corriente e invertidamente comprendido? Bendita sea la glorificación de la sexualidad sublimada, en una criatura de milagro como lo fué Delmira; lo que más nos mueva a comprender a la poetisa, en la ascensión de su carne atormentada de pasta celeste a las regiones de lo metafísico; abstracción sonora la suya en su clamor inolvidable, disuelto el ser en el propio ímpetu de su canto. Clamor de agonía triunfante, o de sombrío júbilo, voluptuosidad dolorosa en su desprendimiento del madero como ser humano y tangible, con todas las miserias y grandezas de su viacrucis para el albur de su destino de tierra...

Pensad por un momento en el medio en que le cupo actuar; su adolescencia concentrada y loca por descubrirse íntegra dentro de sí misma. Su introversión buscando el modo de extravertirse sin alarmas para el çontrol de la moral corriente de su suspicaz medio ambiente. Esta sensibilidad excepcional llevada como un lastre o un estigma. Hasta en el grado de pesadumbre en que se contempló, siempre sonriendo a los otros, crecer y hacerse mujer, llevando la llaga luminosa de su feminidad poderosa $\therefore$. Y en el grito mordido primero, lanzado a los caminos del mundo después, atravesando el velo gris de una atmósfera convencional, pretenciosa, ingenua de imágenes de calcomanías que no podía admitir la desnudez de sus dioses... ni su vuelo audaz.

Porque, mientras Delmira cantaba su emancipación lírica, América mujer, apenas atisbaba por los visillos de la solariega ventana el gesto osado de aquellas primeras feministas que allá, en Europa, asustaban a los hombres conscientes de su monopolio de derechos políticos y civiles. Las crónicas nos traían el trasunto poco afortunado 
de las primeras sufragistas inglesas, con su tenaz afán reivindicativo, con su militancia áspera, tristes y renunciantes a los halagos comunes a la mayoría de las mujeres de la época... sin belleza, sin sueños de carne. Ya vendrían después, reconquistadas a su feminidad graciosa, las otras, más convincentes por dulces y risueñas, por más mimadas, o por nacer más tarde, a engrosar las filas de las triunfadoras feministas: las discípulas, hijas, nietas de aquellas valientes militantes sin coquetería, sin sortilegios.

Desde aquí, Delmira las sobrepasó en un audaz salto de valla. Aventura de stu subconsciente, con arte insuperable. Desnudó la estatua. Como Friné, borró el ceño fruncido de sus jueces, convenciéndolos de que el pecado no puede existir en la belleza.

$Y$, más allá de la verdad de su conciencia poética, lo afirmó rotundamente como ciudadana del mundo, desafiando con su pensamiento audaz, con su alma desnuda de prejuicios, con su interrogante metafísico que subía más allá del techo de su ciudad tranquila de convalecientes, su destino de criatura mesiánica, incendiando las zarzas para abrir el camino a sus hermanas que, como ella, siendo profundamente mujeres, podían decir como justificación de su vocación de arte, el documento vivo de su humanidad sensorial y consciente: alma y carne traspasadas por la divina llama de la Vida intensa.

Oíd la audacia maravillosa con que, nueva Leda, revive líricamente el mito de los dioses griegos, para auscultar, en un friso vivo de voluptuosa angustia, su carne intocada frente al enigma de Eros:

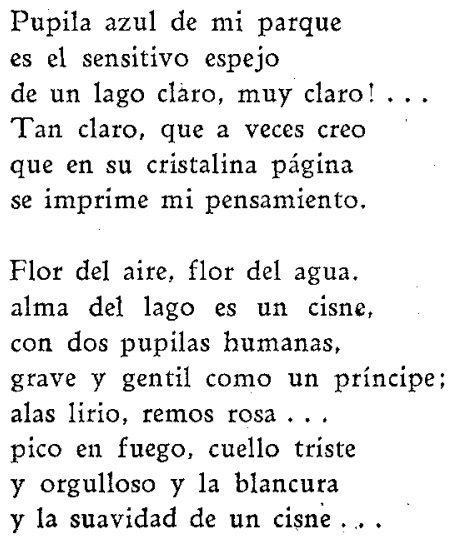


El ave cándida y grave tiene un maléfico encanto. -clavel vestido de lirio, trasciende a llama y milagro! Sus alas blancas me turban como dos cálidos brazos; ningunos labios besaron como su pico mis manos; ninguna testa ha caído tan lánguida en mi regazo; ninguna carne tan viva he padecido o gozado; viborean en sus venas filtros dos veces humanos:

Del rubí de la lujuria su testa está coronada; y va arrastrando el deseo en una cauda rosada... Agua le doy en mis manos y él parece beber fuego; $y$ yo parezco of recerle todo el vaso de mi cuerpo...

$Y$ vive tanto en mis sueños, $y$ ahonda tanto en mi carne, que a veces pienso si el cisne con sus dos alas fugaces, sus raros ojos humanos y el rojo pico quemante, es sólo un cisne en mi lago, o es en mi vida un amante...

A1 margen del lago claro, yo le interrogo en silencio... $Y$ el silencio es una rosa sobre su pico de fuego... Pero en su. carne me habla, $y$ yo en mi carne lo entiendo. -A veces toda! soy alma; $y$ a veces toda! soy cuerpo. Hunde el píco en mi regazo y se queda como muerto... $Y$ en la cristalina página, en el sensitivo espejo del lago que algunas veces 
refleja mi pensamiento,

el cisne asusta de rojo,

y yo de blanca, doy miedo! ...

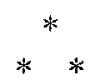

El instinto erótico francamente develado en la imagen poética, eclosiona al recrear la plástica literaria, forma de arte amada por Delmira. Mas, vuelta a su estatua serena de símiles ardientes, se inclina dolida de su vocación de astro para el ígneo rastro. Taciturna y escéptica, se refugia en su añoranza melancólica, suave recordación de su paisaje subjetivo: son los deliciosos "Relicarios dulces", del que extraemos éste:

Hace tiempo, algún alma ya borrada fué mía...

Se nutrió de mi sombra... siempre que yo quería.

el abanico de oro de su risa se abria,

o su llanto sangraba una corriente más;

Alma que yo ondulaba tal una cabellera derramada en mis manos... Flor del fuego y la cera, murió de una tristeza mía... Tan dúctil era,

tan fiel, que a veces dudo si pudo ser jamás...

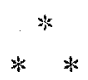

Y vuelve a erguirse. La acucia la tremenda angustia de un stıeño inenarrable: sueño milagroso, con raíces eléctricas, que incendian todos los leves matices. Juzgando mezquinos los deseos de los hombres, el propio Deseo tórnase Dios. La febril tortura torna magnífica la ambición inconmensurable, tal "Lo Inefable", no por tan conocido menos grande, de sus Cantos de la mañana:

Yo muero extrañamente. . No me mata la Vida,

No me mata la Muerte... no me mata el Amor;

Muero de un pensamiento mudo como una herida...

¿No habéis sentido nunca el extraño dolor

De un pensamientò inmenso que se arraiga en la vida

Devorando alma y carne y no alcanza a dar flor? 
¿Nunca llevasteis dentro una estrella dormida que os abrasaba enteros y no daba un fulgor?

Cumbre de los martirios!. . Llevar eternamente

Desgarradora y árida la trágica simiente clavada en las entrañas como un diente feroz!...

Pero arrancarla un día en una flor que abriera Milagrosa, inviolable!... Ah! más grande no fuera tener entre las manos la cabeza de Dios:

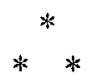

Delmira misma, consciente de su destino de flor sombría, nos lo dice :

Hay noches negras, negras, que llevan en la frente una rosa de sol.

En estas noches negras y claras no se duerme...

Amorosa desde el vórtice de su feminidad esencial, afirma su sueño del amor:

Yo lo soñé impetuoso, formidable y ardiente, hablaba el impetuoso lenguaje del torrente: era un mar desbordado de locura y de fuego, rodando por la vida como un eterno ruego...

Sueño juvenil, y sueño maduro, era un Teseo violento e impetuoso, rendido y fuerte, desbordando ternuras de fuego. : Pobre romántica! La vida habría de achicarle el sueño, hasta tornar absurdo e irónico el nudo deshecho de dos sensibilidades dispares que acallara trágicamente la Muerte.

Flor inmensa - dijimos-, extraña, de un jardín embrujado por una luna amarilla de cirio, donde fingen cruces las ramas desnudas. Jardines Iunáticos que cantara Baudelaire con desgarrada mueca de sonrisa. Flores de parterres lejanísimos, neuróticos, donde se alzan del humus humano las corolas fastuosas con aroma de pecado...

En este verso que tituló "Nocturno", la carne está macerada de deseos supliciantes; mas su erotismo es hierático, tiene algo de sagrado. Como la criatura maldita, invoca a la castidad del lirio y a la piadosa caricia fría del invierno para el connubio de su castigado ardor y de su sed de blancura redentora de un cerebralismo afiebrado. 
De él tornará luego a su deliquio níveo con uno de sus poemas románticos, que tiene muchos, casi pueriles, sustrayéndose a la solicitación peligrosa. Acaso quiere apagar la combustión ígnea de su lirismo con la realidad acerba de lo concreto desolador, cambiando el decorado abstracto del stueño...

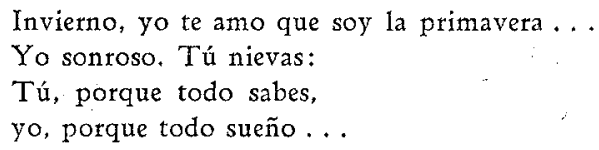

Se abruma de deprimente tristeza. Lo afirma la gráfica de su verso casi siempre. Es el choque psíquico de la arcilla encendida de vuelo, frente a la realidad que deshace constantemente su concreción de horizontes... Goce masoquista nos revela su hiperestesia. La vuelca en este verso que tituló "El arroyo", donde parece quedar suspendida una caliente lágrima rebelde de sus pestañas temblorosas. ¿Ah, los ojos glaucos y enormes de Delmira! ¿Quién equivocadamente la llamó morena y de crenchas renegridas como a una gitana del Albaicín?... Fué sin duda uno de nuestros jóvenes poetas quien recordó solamente que Delmira tenía gotas de sangre ibérica ... Yo la sueño mejor, una Walkyria enternecida, aquella que nos legara Wagner, por la secular leyenda escandinava, herida de muerte por el amor del temerario Sigfrido... ¿Acaso no tenía ella sangre alemana en las venas?... Sí. La impetuosa sangre lírica de un Schiller, de un Goethe, de un Beethoven... de nuestros antiguos amigos venerados. $Y$ era también un poco como una Madonna de Guido Reni, o mejor, aquella Magdalena que se oprime el seno turgente, mientras alza sus ojos al cielo. También Delmira tenía sangre italiana, de la Italia meridional ... Debió pintarla el artista boloñés, con sus párpados pesados, su cuello ebúrneo, su boca sensual y triste, como abrumada, fatigada del beso inmaterial al hombre y a la estrella...

Escuchad su verso "El arroyo". Nos quedará flotando una tristeza de alas sombrías. "La chair es triste, hélas!" - dijo el poeta. Y el Eclesiastés llora su Mea culpa cristiana, tras la voluptuosa melodía del Cantar de los Cantares...

¿Te acuerdas? ... El arroyo fué la serpiente buena.

Fluía triste y triste como un llanto de ciego, cuando en las piedras grises donde arraiga la pena, como un inmenso lirio, se levantó tu ruego. 
Mi corazón - la piedra más gris y más serenadespertó en la caricia de la corriente, y luego, sintió cómo la tarde, con manos de agareria, prendía sobre él una rosa de fuego.

$Y$, mientras la serpiente del arroyo blandía el veneno divino de la melancolía, tocada de crepúsculo me abrumó tu cabeza.

La coroné de un beso fatal; en la corriente vi pasar un cadáver de fuego... Y, locamente, me derrumbó en tu abrazo profundo la Tristeza.

Pero había en Delmira demasiada savia, demasiada vida, y quería ella estrujarla y trizarla, como Beethoven, entre sus puños ávidos de encerrar los átomos vitales del astro. Ardidas las manos, vencido su cuerpo de criatura humana, solloza su magnífico dolor de vivir soñando y desgarrándose, dándose como una fuente de lirismo inagotable. En su delicioso poema "Intima", es sólo la dulce mujer mecida sobre otro corazón fraterno. La vemos ahí, los ojos cerrados, la boca amarga y sonriente, con la beatitud de la hora dulce, como un pétalo azul sobre la mejilla serena...

Mas Delmira vuelve a ser ella, la torturada, la del grito inenarrable, en su dolida vocación de amar y de soñar multiplicando las imágenes del sueño. Es como una música desgarrada y salvaje, gemido dulce a veces, sollozo ululante otras. Su cabeza leonina se tiende al fin desmadejada sobre la almohada del mármol ardiente de los deseos incumplidos...

Humana, nos evoca la tragedia intensa de todas las muertes de la vida; su llaga lírica desborda ríos de sangre caliente. Hay como una desesperada sed de flagelación religiosa en la poética delmiriana. Su mística es de dolor y de fuego: escuchad el enorme poema "Mis amores". ¿Qué mujer pudo superar el grito de Delmira? ¿Su delirio sombrío y su poderosa fuerza de la imagen?...

Hoy han vuelto.

Por todos los senderos de la noche han venido

A llorar en mi lecho.

Fueron tantos!

Son tantos!

Yo no sé cuáles viven. Yo no sé cuál ha muerto.

Me lloraré yo misma para llorarlos todos.

La noche bebe el llanto como un pañuelo negro. 
Hay cabezas doradas a sol, como maduras... Hay cabezas tocadas de sombra y de misterio, cabezas coronadas de una espina invisible, cabezas que se doblan a cojines de abismo, cabezas que quisieran descansar en el cielo. Algunas que no alcanzan a oler a primavera, $y$ muchas que trascienden a las flores de inviemo.

Todas estas cabezas me duelen como liagas...

Me duelen como muertos...

Ah! . . y los ojos... los ojos me duelen más: son dobles!...

Indefinidos, verdes, grises, azules, negros:

abrasan si fulguran,

son caricias, dolor, constelación, infierno.

Sobre toda su luz, sobre todas sus llamas, se iluminó mi alma y se templó mi cuerpo.

-Ellos me dieron sed de todas esas bocas...

De todas esas bocas que florecen mi lecho:

Vasos rojos o pálidos de miel o de amargura, con lises de armonía o rosas de silencio.

de todos esos vasos donde bebí la vida.

de todos esos vasos donde la muerte bebo...

E1 jardin de sus bocas venenoso, embriagante.

en donde respiraba sus almas y sus cuerpos,

humedecido en lágrimas

ha cercado mi lecho...

Y las manos... las manos colmadas de destinos secretos y alhajadas de anillos de misterio... Hay manos que nacieron con guantes de caricia. manos que están colmadas de la flor del deseo. manos en que se siente un puñal nunca visto, manos en que se ve un intangible cetro; pálidas o morenas, voluptuosas o fuertes, en todas, todas ellas, puede engarzar un sueño...

Con tristeza de almas se doblegan los cuerpos, sin velos, santamente, vestidos de deseo.

Imanes de mis brazos, panales de mi entraña, como a invisible abismo se inclinan a mi lecho...

Ah! entre todas las manos, yo he buscado tus manos!

Tu boca entre las bocas, tu cuerpo entre los cuerpos!

De todas las cabezas yo quiero tu cabeza, de todos esos ojos, tus ojos sólo quiero! 
Tú eres el más triste por ser el más querido. tú has llegado el primero por venir de más lejos...

Ah! la cabeza oscura que no he tocado nunca, y las pupilas claras que miré tanto tiempo! Las ojeras que ahondamos la tarde y yo inconscientes, la palidez extraña que doblé sin saberlo!

Ven a mi! mente a mente! Ven a mí! cuerpo a cuerpo!

Tú me dirás qué has hecho de mi primer suspiro!

'Tú me dirás qué has hecho del sueño de aquel beso... Me dirás si lloraste cuando te dejé solo...

$Y$ me dirás si has muerto $! .$.

Si has muerto...

Mi pena enlutará la alcoba lentamente,

y estrecharé tu sombra hasta apagar mi cuerpo.

$Y$ en el silencio ahondado de tiniebla,

$y$ en la tiniebla ahondada de silencio,

nos velará llorando, llorando hasta morirse,

nuestro hijo: el recuerdo.

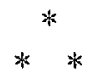

Esta fué Delmira.

Dejadla con su maravilloso complejo de criatura genial en su inconmensurable raíz de infinito. Su inteligencia máscula y su finísima sensibilidad de mujer. De mujer amorosa y taciturna. Acaso ella no quiso ser más que esto: una flor en la noche. De pétalos de carne y de musgo. Herida por el fuego y por la sombra, al borde mismo de la linfa pura, a la que inútil, implacablemente, no logró la sedienta raíz, para colmar su sed de purezas. Era demasiado grande su vida, para esta vida. Estaba más allá del medio, del clima, hilo estelar enredado en la más oculta encrucijada telúrica. Ella nos lo dijo en "Flor nocturna" :

Hastiada siempre de lumbres!

Siempre de sombras sedienta!

Ema Santandreu Morales, Montevideo. 
